\title{
Clinicopathologic profile of squamous cell carcinomas in resected specimens of upper aerodigestive tract: A retrospective study of 72 cases
}

\author{
Gitanjali Monnappa $^{1}$, Priyadarshini Monnappa ${ }^{2, *}$, Hasaf Mubeen Kolakkadan ${ }^{3}$ \\ ${ }^{1-3}$ Assistant Professor, Dept. of Pathology, ${ }^{1,3}$ DMWIMS Medical College, Wayanad, Kerala, ${ }^{2}$ Kodagu Institute of Medical \\ Sciences, Madikeri, Karnataka, India
}

*Corresponding Author:

Email: piyadarsh@gmail.com

\begin{abstract}
Background: Malignancies of head and neck, especially oral cancers are aggressive epithelial cancers and its incidence is specially high in developing countries like India. Few of the common risk factors associated with these tumours are cigarette smoking, alcohol intake and tobacco chewing. These tumours pose a serious public health issue since majority of these patients present at advanced stage of the disease. This study was aimed to evaluate the clinicopathologic characteristics and demographic data associated with squamous cell carcinomas (SCC) of head and neck.

Material and Methods: This is a retrospective study conducted in 72 resected specimens of malignancies of Head and Neck over a three year study period.

Results: A female predominance was noted $(\mathrm{M}: \mathrm{F}=0.5: 1)$ with majority in age group between 40-50years. Commonest site was in oral cavity, especially in buccal mucosa and this was seen more often in females. Cigarette smoking was more commonly seen in males when compared to females and the difference was statistically significant $(\mathrm{p}<0.00001)$, while tobacco chewing was commonly seen in females than males, the difference was statistically insignificant. There were almost equal number of well and moderately differentiated tumours with $40 \%$ of total cases showing lymph node metastasis at time of presentation.

Conclusion: The occurrence of most of these tumours in oral cavity buccal mucosa and in females could be linked to the tobacco chewing practice in this population. A proper and strict community education and awareness could possibly lead to decrease its incidence.
\end{abstract}

Keywords: Head and neck Squamous cell carcinoma, Oral cavity, Smoking, Tobacco chewing.

\section{Introduction}

Among the various malignant tumours that originate in the oral cavity, squamous cell carcinomas (SCC) constitutes a significant proportion comprising 95\% of head and neck cancers. ${ }^{1}$ These aggressive epithelial malignancies account for about one third of cases in the Indian subcontinent alone. ${ }^{2}$ Head and neck Squamous cell carcinoma (HNSCC) represents one of the sixth most common cancers in the world and pose a significant public health challenge. ${ }^{3}$

Environmental and lifestyle-related factors such as use of tobacco, cigarette smoking, consumption of alcohol, human papilloma virus infection, dietary factors and exposure to toxic substances are major influences that play a role in the etiology and pathogenesis of HNSCC. ${ }^{4}$ HNSCC are primarily not hereditary, but a disease that affects mainly the older and middle aged adults who usually give a long history of tobacco smoking. The prevalence is more common in developing countries such as India and Indonesia where the population chew betel quid - betel nut (Areca catechu) which is wrapped in betel leaf, sometimes mixed with lime. Use of snuff also increases the risk of developing oral cancer. ${ }^{5}$

It is seen that consumption alcohol interacts with tobacco use to increase the risk of HNSCC and there is a strong dose-response relationship for both alcohol and tobacco consumption in virtually all of the HNSCC studies published to date. ${ }^{6}$ As highlighted by Forastiere
A et al in their study, progressive accumulation of genetic alterations leads to the progression of head and neck cancer, from a simple squamous hyperplasia through the advancing stages of squamous dysplasia to invasive squamous cell carcinoma. ${ }^{7}$ These lesions present mainly in the buccal mucosa of the oral cavity, followed by the tongue, floor of the mouth and lower lip. ${ }^{8}$

The precursor lesions may present as leukoplakia, erythroplakia or speckled erythroplakia. The World Health Organisation has classified Squamous cell carcinomas into numerous histological types, the most common being the conventional type. ${ }^{9}$ The histologic grade of the malignant lesions may predict its biologic behaviour, the grade I tumours being less aggressive and showing metastasis at a later period of time, where as grade III tumours being more aggressive and metastasising earlier in the stage of the disease. ${ }^{8}$

The present study was conducted to evaluate the various demographic data like age, sex, clinical history, site and type of squamous cell carcinomas of head and neck and to correlate this data with the size of tumour, its grade and lymph node metastasis.

\section{Materials and Methods}

The present retrospective study was conducted in Pathology department over a three year period from January 2010 to January 2013 where we received 72 resected specimens for malignancies of head and neck. 
All the demographic data and clinical history with relevant investigations done was collected from the patients' records. The specimen was received in $10 \%$ formalin and standard protocol for surgical grossing of the specimens was followed. Multiple sections were taken from the tumor and all the lymph nodes.

Processed paraffin embedded sections were stained by haematoxylin and $\operatorname{eosin}(\mathrm{H} \quad \& \quad \mathrm{E})$ for histopathological study. The tumours were studied and classified according to the Broder's grading system.

\section{Statistical Analysis}

The data was represented in terms of frequency distribution tables. Statistical significance was employed using chi-square test. $\mathrm{P} \leq 0.05$ was considered statistically significant.

\section{Results}

Of the 72 cases, majority were females $47(65 \%)$ and $25(35 \%)$ were males, with a $\mathrm{F}$ : $\mathrm{M}$ ratio of $2: 1$. Most cases were seen in the age group between 41-50 years followed by 51-60 years. The patients mainly presented with an ulcerative lesion in the oral cavity (72\%) and gave history of odynophagia. Few of the common clinical history provided by patients was cigarette smoking (25/72), tobacco chewing (50/72) and alcohol intake (29/72). Cigarette smoking was more commonly seen in males $(20 / 25)$ when compared to females $(5 / 25)$ and the difference was statistically significant $(\mathrm{p}<0.00001)$. Of the $50 / 72$ tobacco chewers, majority $(35 / 50)$ were females when compared to $15 / 50$ males, although the difference was statistically insignificant $(\mathrm{p}=0.2)$.

Table 1: Distribution of cases based on tobacco chewing/alcohol intake/smoking

\begin{tabular}{|l|c|c|c|c|}
\hline & Females & Males & Total & Percentage \\
\hline Buccal mucosa & 36 & 12 & 48 & $66.6 \%$ \\
\hline Tongue & 1 & 4 & 5 & $6.9 \%$ \\
\hline Retromolar trigone & 7 & 1 & 8 & $11.1 \%$ \\
\hline Palate & 0 & 1 & 1 & $1.4 \%$ \\
\hline Lip & 0 & 1 & 1 & $1.4 \%$ \\
\hline Alveolus & 2 & 3 & 5 & $6.9 \%$ \\
\hline Nasal cavity & 0 & 1 & 1 & $1.4 \%$ \\
\hline Pharynx & 0 & 1 & 1 & $1.4 \%$ \\
\hline Subglottis & 0 & 1 & 1 & $1.4 \%$ \\
\hline Maxilla & 1 & 0 & 1 & $1.4 \%$ \\
\hline Total & 47 & 25 & 72 & $100 \%$ \\
\hline
\end{tabular}

Gross appearance of the tumour: On gross examination, a greater part of the cases had an ulceroinfiltrative appearance with irregular margins and sloughed ulcer base. Rest of the tumours showed ulceroproliferative/ warty/ nodular appearance.

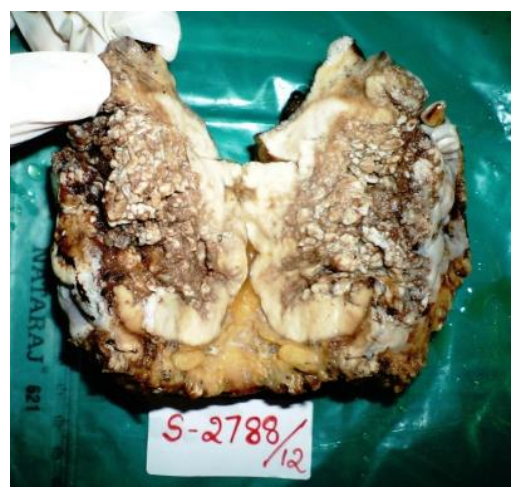

Fig. 1: A fungating grey white cauliflower-like growth in the hard palate

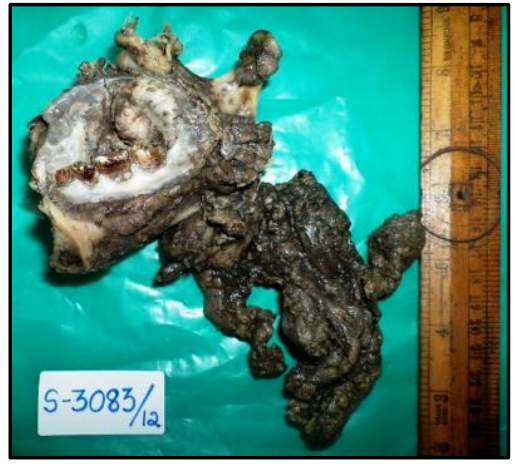

Fig. 2: Right Hemimandibulectomy: A gray white ulceroinfiltrative growth at the mandibular ramus

Tumour size: In majority of the cases 34/72 (47\%), the tumour size was between $2.1-4 \mathrm{~cm}$. $28 \%$ of cases had tumour size $>4.1 \mathrm{~cm}$ and in remaining $25 \%$ the size was $<2 \mathrm{~cm}$. There was no statistical significance in the size of tumor seen in females and males $(\mathrm{p}=0.8)$.

Tumour site: $68 / 72(95 \%)$ cases had tumour in the oral cavity, especially in the buccal mucosa (48/68). Of the $48 / 68$ cases in the buccal mucosa, $36 / 48$ cases was seen in females and 12/48 cases was seen in males and the difference was statistically significant $(\mathrm{p}=0.01)$. The 
abundance of tumours in the buccal mucosa seen mainly in females could be due to the increased habit of tobacco chewing in this population. Other areas affected in the oral cavity was the tongue, lips and palate.

Less common sites were in the pharynx, larynx, nasal cavity and maxillary sinus.

Table 2: Distribution of cases according to the site

\begin{tabular}{|l|c|c|c|c|c|c|}
\hline \multirow{2}{*}{} & \multicolumn{2}{|c|}{ Tobacco } & \multicolumn{2}{c|}{ Alcohol } & \multicolumn{2}{c|}{ Smoking } \\
\cline { 2 - 7 } & Yes & No & Yes & No & Yes & No \\
\hline Females & 35 & 12 & 16 & 31 & 5 & 42 \\
\hline Males & 15 & 10 & 13 & 12 & 20 & 5 \\
\hline Total & 50 & 22 & 29 & 43 & 25 & 47 \\
\hline & \multicolumn{2}{|c|}{$\mathrm{P}=0.2$} & \multicolumn{2}{c|}{$\mathrm{P}=0.13$} & $\mathrm{P}<0.00001$ \\
\hline
\end{tabular}

Tumour Grade: Most of the tumours were well $(35 / 72)$ or moderately differentiated $(36 / 72)$. There was only one case of poorly differentiated tumour. The difference in the grades of tumour between the sexes was not statistically significant $(\mathrm{p}=0.98)$.

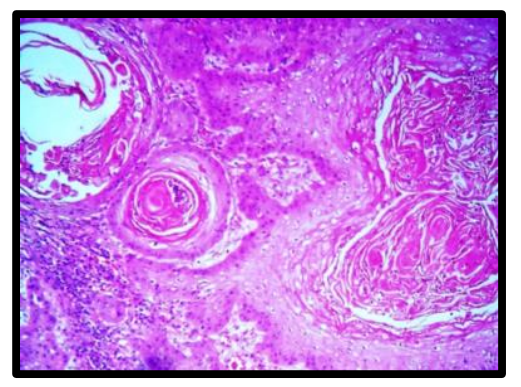

Fig. 3: Well differentiated Squamous cell carcinoma showing mildly pleomorphic squamous cells in sheets with keratin pearls. (H\&E, x100)

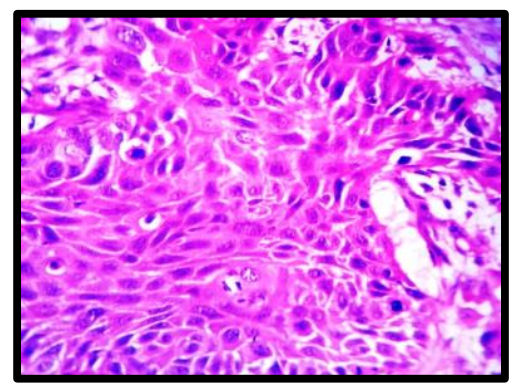

Fig. 4: Moderately differentiated squamous cell carcinoma showing moderately pleomorphic squamous cells and mitotic figures. (H\&E, x400)

Lymph node metastases: 32/72 (40\%) cases had lymph node metastases at the time of presentation. Of the 32 cases, $23(71.8 \%)$ showed presence of perinodal spread. There was no statistical significance between the lymph node metastasis and age of the patient $(p=0.15)$, sex $(p=0.9)$, size of tumor $(p=0.37)$ and grade of tumour $(\mathrm{p}=0.6)$.
Lymphatic/Venous/ Perineurial invasion: Of the 72 cases, 23/72 (31.9\%), 12/72 (16.6\%) and 14/72 (19.4\%) cases had lymphatic invasion, venous invasion and perineural invasion respectively.

Stage of tumour: Of the 72 cases, 49 were in stage III/IV at the time of diagnosis and 23 were in stage I/II.

\section{Discussion}

Among the 72 cases of HNSCC studied, it was observed that the mean age of presentation of the patients in our study was almost 10years younger when compared to studies done by Mariezkurrena XA et al. ${ }^{10}$ and Payne CW et al. ${ }^{11}$

Our study showed a female preponderance with a F:M ratio of 2:1. Previous studies by Chung $\mathrm{CH}$ et al., ${ }^{12}$ Payne CW et al., ${ }^{11}$ Hsiung DT et al., ${ }^{13}$ Keller J et al., ${ }^{14}$ Issa $\mathrm{HI}^{15}$ showed predominance of cases in males. This difference could be attributed to the females in the present set up who chew tobacco and betel nut on a regular basis and such habits is more prevalent in the lower socioeconomic group.

Table 3: Comparing Male: Female (M:F) ratio in various studies

\begin{tabular}{|l|c|c|}
\hline \multicolumn{1}{|c|}{ Study } & M:F ratio & Year of study \\
\hline Chung CH et al. $^{12}$ & $5.8: 1$ & 2006 \\
\hline Payne CW et al. $^{11}$ & $11: 1$ & 2006 \\
\hline Hsiung DT et al. $^{13}$ & $2.2: 1$ & 2007 \\
\hline Keller J et al. & \\
\hline Issa HI $^{15}$ & $3: 1$ & 2010 \\
\hline Rai HC $^{8}$ & $2.3: 1$ & 2013 \\
\hline Sarode GS & $1.1: 1$ & 2015 \\
\hline Present study & $1.7: 1$ & 2015 \\
\hline
\end{tabular}

Long-term use of smokeless tobacco increases the risk of HNSCC as observed by Zhou J et al. ${ }^{16}$ Also, Tobacco in both smoked and smokeless forms is the most important risk factor for both development and prognosis of HNSCCs and may be a major source of field cancerization on the head and neck epithelium (Basu R et al.). ${ }^{5}$ It was seen in the present study that there was a high prevalence of tobacco intake which was similar to that seen in previous studies by Maiti GP et al. ${ }^{17}$ and Huang SF et al. ${ }^{18}$

We have observed that most of the HNSCC in our study was present in the oral cavity when compared to previous studies by Mariezkurrena XA et al., ${ }^{10}$ Chung $\mathrm{CH}$ et al., ${ }^{12}$ Hama T et al. ${ }^{19}$ and Hsiung DT et al. ${ }^{13}$ One third to one half of Head and Neck malignancies in most parts of the world usually occur in the larynx and nasopharynx, as highlighted by Basu R et al., ${ }^{5}$ whereas, in South-Central Asia, $80 \%$ of head and neck cancers are found in the oral cavity and oropharynx. The habit of tobacco chewing that is more prevalent in South Central Asian countries like ours could explain the increased incidence of SCCs in oral cavity. 
Table 4: Comparison of the most common site of presentation of the tumour in various studies

\begin{tabular}{|l|c|c|c|c|c|}
\hline \multicolumn{1}{|c|}{ Study } & Oral cavity & Pharynx & Larynx & Others & Total \\
\hline Mariezkurrena XA et al. ${ }^{10}$ & - & $23(52.0 \%)$ & $18(41.0 \%)$ & $3(7.0 \%)$ & 44 \\
\hline Chung CH et al. ${ }^{12}$ & $23(30.6 \%)$ & $25(33.3 \%)$ & $27(36.0 \%)$ & - & 75 \\
\hline Issa HI $^{15}$ & $8(26.7 \%)$ & $9(30.0 \%)$ & $7(23.3 \%)$ & $6(20.0 \%)$ & 30 \\
\hline Hsiung DT et al. $^{13}$ & $10(30.3 \%)$ & $4(12.2 \%)$ & $19(57.6 \%)$ & - & 33 \\
\hline Hama T et al. $^{19}$ & $33(40.2 \%)$ & $22(26.8 \%)$ & $19(23.3 \%)$ & $8(9.7 \%)$ & 82 \\
\hline Present study & $68(94.5 \%)$ & $1(1.4 \%)$ & $1(1.4 \%)$ & $2(2.7 \%)$ & 72 \\
\hline
\end{tabular}

Compared to other studies, the number of grade 3 tumours in this study was relatively less, where as there is no much difference in the number of grade 1 and grade 2 tumours. This study had only one case of poorly differentiated tumour while the rest of the cases were well/ moderately differentiated.

Table 5: Comparison of grade of tumour at the time of presentation in various studies

\begin{tabular}{|l|c|c|c|c|}
\hline \multicolumn{1}{|c|}{ Author } & Year & Grade I & Grade II & Grade III \\
\hline Mariezkurrena XA et al. ${ }^{10}$ & 2005 & $14(31.8 \%)$ & $17(38.6 \%)$ & $13(29.5 \%)$ \\
\hline Hama T et al. $^{19}$ & 2009 & $30(36.5 \%)$ & $36(46.5 \%)$ & $16(17.0 \%)$ \\
\hline Issa HI $^{15}$ & 2013 & $6(20.0 \%)$ & $13(43.3 \%)$ & $11(36.7 \%)$ \\
\hline Rai HC $^{8}$ & 2015 & $66(50.8 \%)$ & $38(29.2 \%)$ & $26(20 \%)$ \\
\hline Smitha T et al. & & & \\
\hline Present study & 2017 & $137(46 \%)$ & $135(45.5 \%)$ & $25(8.5 \%)$ \\
\hline
\end{tabular}

\section{Conclusion}

Squamous cell carcinomas of the head and neck with advanced primary lesions, with or without regional lymph-node metastases, are challenging to treat effectively and the outcome of patients presenting with advanced stage of the disease still remains poor. A detailed study about the various etiological factors associated with HNSCC and a proper awareness and education to the population regarding the same could possibly lead to a decrease in its incidence.

\section{Acknowledgement}

I would like to thank Dr. Priyadarshini Monnappa for her help in preparing the manuscript.

\section{Conflicts of interest: None}

Funding: No funding sources.

Conflict of interest: None declared.

\section{References}

1. Majumdar B, Patil S, Sarode SC, Sarode GS, Rao RS. Clinico-pathological prognosticators in oral squamous cell carcinoma: An update. Translational Res Oral Oncol 2017;2:1-14

2. Sarode GS, Sarode SC, Kulkarni M, Karmarkar S, Patil SG, Augustine D. Bioimpedance Assessment of Oral Squamous Cell Carcinoma with Clinicopathological Correlation. J Contemporary Dent Practice 2015;16(9):18.

3. Parkin DM, Bray F, Ferlay J, Pisani P. Global cancer statistics. CA Cancer J Clin 2002;55(2):74-108.

4. Baez A. Genetic and environmental factors in head and neck cancer genesis. Journal of environmental science and health Part C Environmental carcinogenesis ecotoxicology reviews 2011;26(2):174-200.

5. Basu R, Mandal S, Ghosh A, Poddar TK. Role of Tobacco in the Development of Head and Neck
Squamous Cell Carcinoma in an Eastern Indian Population. Asian Pacific J Cancer Prev 2008;9:381-86.

6. Peters ES, McClean MD, Liu M, Eisen EA, Mueller N and Kelsey KT. The ADH1C Polymorphism Modifies the Risk of Squamous Cell Carcinoma of the Head and Neck Associated with Alcohol and Tobacco Use. Cancer Epidemiol Biomarkers Prev 2005;14(2):476-82.

7. Forastiere A, Koch W, Trotti A and Sidransky D. Head and neck cancer. N Engl J Med 2001;345(26):1890-900.

8. Rai HC, Ahmed J. Clinicopathological Correlation Study of Oral Squamous Cell Carcinoma in a Local Indian Population. Asian Pacific J Cancer Prev 2015;17:125154.

9. Humphrey PA, Dehner LP, Pfeifer JD. Head and Neck. In: The Washington Manual of Surgical Pathology. $2^{\text {nd }}$ ed. Philadelphia: Lippincott Williams \& Wilkins; 2012;149.

10. Mariezkurrena XA, Guimera JA, Rodriguez JW, Weisman R, Ongkeko W. Immunohistochemistry study of EGFR expression in head and neck squamous cell carcinoma. Acta Otorrinolaringol Esp 2005;56:143-46.

11. Payne CW, Holden JA and Layfield LJ. Detection of EGFR- and HER2-activating mutations in squamous cell carcinoma involving the head and neck. Modern Pathol 2006;16:634-40.

12. Chung CH, Ely K, McGavran L, Garcia MV, Parker J, Parker $\mathrm{N}$ et al. Increased Epidermal Growth Factor Receptor Gene Copy Number Is Associated With Poor Prognosis in Head and Neck Squamous Cell Carcinomas. $J$ Clin Oncol 2006;24(25):4170-76.

13. Hsiung DT, Marsit CJ, Houseman A, Eddy K, Furniss CS, McClean MD et al. Global DNA Methylation Level in Whole Blood as a Biomarker in Head and Neck Squamous Cell Carcinoma. Cancer Epidemiol Biomarkers Prev 2007;16(1):108-14.

14. Keller J, Shroyer KR, Batajoo SK, Zhao HL, Dong LM, Hayman MJ et al. Combination of Phosphorylated and Truncated EGFR Correlates With Higher Tumor and Nodal Stage in Head and Neck Cancer. Cancer Invest 2010;28(10):1054-62. 
15. Issa HI. Immunoexpression of Epidermal Growth Factor Receptor, Ki-67 and P53 Protein in Squamous Cell Carcinoma of the Head and Neck. Res J Med Med Sci 2013;8(1):9-15.

16. Zhou J, Michaud DS, Langevin SM, McClean MD, Eliot M, Kelsey KT. Smokeless tobacco and risk of head and neck cancer: evidence from a case-control study in New England. Int J Cancer 2013;132(8):1911-17.

17. Maiti GP, Mondal P, Mukherjee N, Ghosh A, Ghosh S, Dey $\mathrm{S}$ et al. Overexpression of EGFR in Head and Neck Squamous Cell Carcinoma Is Associated with Inactivation of SH3GL2 and CDC25A Genes. PLoS ONE 2013;8(5):e63440.

18. Huang SF, Cheng SD, Chien HT, Liao CT, Chen IH, Wange HM et al. Relationship between epidermal growth factor receptor gene copy number and protein expression in oral cavity squamous cell carcinoma. Oral Oncol 2012;48:67-72.

19. Hama T, Yuza Y, Saito Y, O-Uchi J, Kondo S, Okabe M et al. Prognostic Significance of Epidermal Growth Factor Receptor Phosphorylation and Mutation in Head and Neck Squamous Cell Carcinoma. Oncologist 2009;14:900-8.

20. Smitha T, Mohan CV, Hemavathy S. Clinicopathological features of oral squamous cell carcinoma: A hospital-based retrospective study. J Dr. NTR Univ Health Sci 2017;6:29-34.

How to cite this article: Monnappa G., Monnappa P., Kolakkadan H. Clinicopathologic profile of squamous cell carcinomas in resected specimens of upper aerodigestive tract: A retrospective study of 72 cases. J Diagn Pathol Oncol 2018;3(4):263-67. 